\title{
A Study of Relationship of Bone Mineral Density with Age, Body Mass Index, Obesity and Serum Magnesium Level
}

\author{
Jyoti Jaiswal ${ }^{1}$, Anchala Mahilange ${ }^{2}$ \\ 1,2 Department of Obstetrics and Gynaecology, Pt. Jawaharlal Nehru Memorial \\ Medical College, Raipur, Chhattisgarh, India.
}

\section{ABSTRACT}

\section{BACKGROUND}

Menopause is defined as the permanent cessation of menstruation following loss of ovarian activity. One of the most important problems associated with menopause is osteoporosis. This study was conducted to evaluate the relationship between bone mineral density, body mass index, age, serum calcium, and serum magnesium in 120 women.

\section{METHODS}

Present study was an observational study done from Feb 2017 to July 2017 in Pt. J.N.M. Medical College to evaluate the relationship of bone mineral density with age, body mass index (BMI), obesity and serum magnesium in 120 postmenopausal women. A detailed medical, obstetrical, menstrual, and drug history was recorded in a proforma designed for the study. Past fracture history, family history of fracture and osteoporosis, socioeconomic status, occupation, educational level and weightbearing exercises were collected and recorded.

\section{RESULTS}

Average age of women with normal bone health was $30.5 \pm 0.58$ years, while the age of osteopenic and osteoporotic women was $43.11 \pm 6.79$ years and $54.64 \pm 11.92$ years respectively. Most of the osteopenic women belonged to the age group of $40-$ 49 years. Osteoporotic patients $(78.57 \%)$ had a high ( $>0.85)$ waist-hip ratio, while women with normal bone mineral density had a normal waist-hip ratio. Most of the women with normal bone mineral density (100\%), osteopenia (85.29\%) and osteoporosis (57.14 \%) had normal serum magnesium levels.

\section{CONCLUSIONS}

We found that the bone mineral density reduced with advancing age, decreasing BMI and obesity, while we found no correlation of serum magnesium level with bone mineral density (BMD).

\section{KEY WORDS}

Bone Mineral Density, Body Mass Index, Perimenopause, Magnesium, Calcium
Corresponding Author: Dr. Anchala Mahilange, Assistant Professor, F18, Doctors Quarter, Medical College Raipur, Chhattisgarh, India. E-mail: amahilange@gmail.com

DOI: $10.14260 /$ jemds/2021/327

How to Cite This Article:

Jaiswal J, Mahilange A. A study of relationship of bone mineral density with age, body mass index, obesity and serum magnesium level. J Evolution Med Dent Sci 2021;10(21):1563-1566, 10.14260/jemds/2021/327

Submission 25-10-2020, Peer Review 25-03-2021, Acceptance 31-03-2021, Published 24-05-2021.

Copyright (C) 2021 Jyoti Jaiswal et al. This is an open access article distributed under Creative Commons Attribution License [Attribution 4.0 International (CC BY 4.0)] 


\section{BACKGROUND}

Menopause is defined as the permanent cessation of menstruation following loss of ovarian activity. ${ }^{1}$ One of the most important problems associated with menopause is osteoporosis. Osteoporosis is the most common metabolic bone disease and it affects up to $40 \%$ of postmenopausal women. ${ }^{2}$ Peak bone mass is achieved in $3^{\text {rd }}$ decade of life. Approximately, $50 \%$ of bone loss occurs in 5 to 7 years of menopause, ${ }^{3}$ as due to menopause there is lack of oestrogen which leads to increase in osteoclastic activity of bone. A more recent definition from the National Institutes of Health (NIH) consensus development panel on osteoporosis defines osteoporosis as a skeletal disorder characterised by compromised bone strength predisposing a person to an increased risk of fracture. ${ }^{2}$ Osteoporosis is caused by imbalance between bone formation and bone resorption. Bone mineral density is a quantitative measure of bone mass and represents the total mineral in a selected volume of bone in hip or in spine. ${ }^{4}$ Bone mineral density is considered to be the standard measure for diagnosis of osteoporosis and the assessment of fracture risk. Majority of fragility fractures occur in patients with bone mineral density in the osteopenic range. Study group meeting of World Health Organization (WHO) assessed fracture risk and applied it to screen postmenopausal osteoporosis, and recorded that more than 75 million people in US, Europe and Japan were suffering from osteoporosis in 2006. Osteoporosis is a multifactorial disease. Several studies have shown that in addition to risk factors such as aging, lack of physical activity, smoking, premature menopause, family history, poor diet and low intake of calcium and vitamin $\mathrm{D}$, other factors including body weight and body mass index (BMI) are also important in the risk assessment tools, which contribute to osteoporosis and osteoporotic fracture risk. ${ }^{4}$ Low BMI and low weight are also associated with occurrence of osteoporosis. In several studies on different species, dietary magnesium $(\mathrm{Mg})$ restriction promotes osteoporosis. Bones of $\mathrm{Mg}$ deficient animals are brittle and fragile. ${ }^{5}$ Micro fracture and trabeculae can be detected and mechanical properties are severely impaired. So, $\mathrm{Mg}$ deficient diet could be a factor which can lead to osteoporosis. Present observational study was conducted in obstetrics and gynaecology department of Pt. J.N.M. Medical College to see the correlation of bone mineral density with age, body mass index (BMI), obesity and serum magnesium.

\section{Objectives}

Find relationship between bone mineral density with body mass index, age and serum calcium and serum magnesium in 120 women.

\section{METHODS}

The present study was an observational study, which was conducted in the Department of Obstetrics and Gynaecology, Pt. J.N.M. Medical College and Hospital Raipur, India. The study was conducted among 120 postmenopausal women.

A detailed medical, obstetrical, menstrual and drug history was recorded in a proforma designated for the study.
Information on past fracture history, family history of fracture and osteoporosis, socioeconomic status, occupation, educational level and weight-bearing exercises was collected and recorded.

BMI: Weight and height were measured through standard methods and BMI was calculated by dividing weight (kilogram) by height square (square meter).

Classified by Asian pacific classification-

Underweight $-<18.5 \mathrm{Kg} / \mathrm{m}^{2}$

Normal - 18.5 - $22.9 \mathrm{Kg} / \mathrm{m}^{2}$

Overweight $-23-24.9 \mathrm{Kg} / \mathrm{m}^{2}$

Class 1 obese - $>25 \mathrm{Kg} / \mathrm{m}^{2}$

Waist / hip ratio-waist circumference was taken by positioning the tape just above iliac crest parallel to the floor (in centimetre). Hip circumference was measured by widest part of hip (in centimetre). The ratio was calculated. Then classified as (WHO classification ${ }^{6}$ )

$$
\begin{aligned}
& <0.80 \text { - low risk } \\
& 0.81-0.85 \text { - moderate risk } \\
& >0.85 \text { - high risk }
\end{aligned}
$$

The bone mineral density was measured by bone densitometer and classified as normal, osteopenia and osteoporosis according to T-score. Based on WHO classification ${ }^{4}$, individuals with $\mathrm{T}$-score values higher than -1 were classified as normal -

- Those with T-score between -1 and -2.5 as osteopenic

- Those with T-score less than -2.5 as osteoporotic.

Serum mineral was measured in auto-analyser. Blood samples were collected in tubes for estimations of calcium and magnesium after an overnight fast. Calcium and magnesium were estimated by using commercially available kits in ChemWell automated analyser. All post-menopausal women were included in the study.

\section{Exclusion Criteria}

Post-menopausal women with secondary causes of decreased BMD or any other chronic illnesses such as hyperthyroidism, diabetes mellitus, renal or liver disease, rheumatoid arthritis or a history of treatment with levothyroxine, furosemide, heparin, phenytoin, phenobarbital, vitamin $\mathrm{K}$, ranitidine, corticosteroids, alcohol consumption, those having history of fractures, bone deformity and surgical operations were not included in the study.

\section{Statistical Analysis}

Data was entered to Microsoft Access Databank, and analysed using Statistical Package for the Social Sciences (SPSS) 13.0 for Windows (SPSS, Chicago, IL) based on a Pair-wise approach. Pvalues lower than 0.01 were considered statistically significant. Categorical variables were expressed as percentages and compared using chi-square. Differences among means were investigated by analysis of variance (ANOVA) with post-hoc test.

\section{RESULTS}

Table 1 shows that the average age of women with normal bone health was $30.5 \pm 0.58$ years, while the age of osteopenic 
and osteoporotic women was $43.11 \pm 6.79$ years and $54.64 \pm$ 11.92 years respectively. This showed that there was statistically significant (P-value $<0.0001$ ) correlation of age with bone mineral density. Table 1 also shows that average BMI of osteoporotic group was $16.32 \pm 2.08$ while BMI of women with normal bone health was $20.98 \pm 2.47$ which showed statistically significant $(\mathrm{P}$-value $<0.0001)$ correlation of low BMI with low BMD.

Average age of women with normal bone health was 30.5+ 0.58 years, while the age of osteopenic and osteoporotic women was $43.11 \pm 6.79$ years and $54.64 \pm 11.92$ years respectively. There was statistically significant (P-value < 0.0001) correlation of increasing age with bone mineral density. There was no statistical difference in value of calcium level (mg / dl) in blood of normal, osteopenic and osteoporotic group of women.

\begin{tabular}{|cccccc|}
\hline \multicolumn{7}{c|}{$\begin{array}{c}\text { Normal } \\
\text { Bone Health } \\
(\mathbf{N}=\mathbf{4})\end{array}$} & $\begin{array}{c}\text { Osteopenia } \\
\text { Group }\end{array}$ & $\begin{array}{c}\text { Group } \\
(\mathbf{N}=\mathbf{1 0 2})\end{array}$ & $\begin{array}{c}\mathbf{F} \\
(\mathbf{N}=\mathbf{1 4})\end{array}$ & Value & P-Value \\
Age (year) & $30.5 \pm .58$ & $43.11 \pm 6.79$ & $54.64 \pm 11.92$ & 21.55 & $<.0001$ \\
$\mathrm{BMI}(\mathrm{kg} / \mathrm{m} 2)$ & $20.98 \pm 2.47$ & $23.42 \pm 10.93$ & $16.32 \pm 2.08$ & 20.45 & $<.0001$ \\
$\mathrm{Ca}(\mathrm{mg} / \mathrm{dl})$ & $9.9 \pm .23$ & $9.60 \pm 1.35$ & $10.04 \pm .13$ & .82 & .44 \\
$\mathrm{Mg}(\mathrm{mg} / \mathrm{dl})$ & $2.1 \pm .11$ & $2.05 \pm .21$ & $2.25 \pm .11$ & 6.15 & $<.05$ \\
\hline \multicolumn{7}{|c|}{ Table 1. Baseline Characteristics in Women with } \\
Osteoporosis and Osteopenia \\
\hline \multicolumn{7}{|c|}{ Values are calculated through Analysis of variance with post hoc test } \\
\hline
\end{tabular}

\begin{tabular}{|c|c|c|c|c|}
\hline \multicolumn{2}{|c|}{ Variable } & $\begin{array}{l}\text { Normal } \\
(N=4)\end{array}$ & $\begin{array}{c}\text { Osteopenia } \\
(\mathrm{N}=102)\end{array}$ & $\begin{array}{l}\text { Osteoporotic } \\
(\mathrm{N}=14)\end{array}$ \\
\hline \multirow{4}{*}{ Age } & $30-39(\mathrm{~N}=35)$ & $\begin{array}{c}4(100 \%) \\
(3.33 \%)\end{array}$ & $\begin{array}{c}31(30.39 \%) \\
(88.57 \%)\end{array}$ & 0 \\
\hline & $40-49(\mathrm{~N}=55)$ & 0 & $\begin{array}{l}51(50 \%) \\
(92.72 \%)\end{array}$ & $\begin{array}{c}4(28.57 \%) \\
(7.27 \%)\end{array}$ \\
\hline & $50-59(\mathrm{~N}=24)$ & 0 & $\begin{array}{c}19(18.62 \%) \\
(79.16 \%)\end{array}$ & $\begin{array}{c}5(35.71 \%) \\
(20.83 \%)\end{array}$ \\
\hline & $>60(\mathrm{~N}=6)$ & 0 & $\begin{array}{l}1(0.98 \%) \\
(16.66 \%)\end{array}$ & $\begin{array}{c}5(35.71 \%) \\
(83.33 \%)\end{array}$ \\
\hline \multicolumn{5}{|c|}{ Table 2. Correlation of Age with Bone Mineral Density } \\
\hline \multicolumn{5}{|c|}{$\chi 2=46.682$ degree of freedom $=6$, P-value $<.05$} \\
\hline
\end{tabular}

Table 2 shows that all the patients with normal bone mineral density belonged to the age group of $30-39$ years. Most of the osteopenic women belonged to the age group of 40 - 49 years and all the osteoporotic women's age was more than 40 years.

\begin{tabular}{|c|c|c|c|c|}
\hline \multicolumn{2}{|l|}{ Variable } & $\begin{array}{l}\text { Normal } \\
(N=4)\end{array}$ & $\begin{array}{c}\text { Osteopenia } \\
(\mathrm{N}=102)\end{array}$ & $\begin{array}{c}\text { Osteoporotic } \\
(\mathrm{N}=14)\end{array}$ \\
\hline \multirow{3}{*}{$\begin{array}{l}\text { Waist / hip } \\
\text { ratio }\end{array}$} & $\begin{array}{c}<.80 \text { (low risk) } \\
(\mathrm{N}=53)\end{array}$ & $\begin{array}{l}2(50 \%) \\
(3.77 \%)\end{array}$ & $\begin{array}{c}49(48.03 \%) \\
(92.45 \%)\end{array}$ & $\begin{array}{c}2(14.28 \%) \\
(3.77 \%)\end{array}$ \\
\hline & $\begin{array}{c}.81-.85 \\
\text { (moderate risk) } \\
(\mathrm{N}=32)\end{array}$ & $\begin{array}{l}2(50 \%) \\
(6.25 \%)\end{array}$ & $\begin{array}{c}29(28.43 \%) \\
(90.62 \%)\end{array}$ & $\begin{array}{c}1(7.14 \%) \\
(3.12 \%)\end{array}$ \\
\hline & $\begin{array}{c}>.85 \text { (high risk }) \\
(\mathrm{N}=35)\end{array}$ & & $\begin{array}{c}24(23.52 \%) \\
(68.57 \%)\end{array}$ & $\begin{array}{c}11(78.57 \%) \\
(31.42 \%)\end{array}$ \\
\hline \multicolumn{5}{|c|}{ Table 3. Correlation of Waist Hip Ratio with BMD } \\
\hline
\end{tabular}

Table 3 shows that $78.57 \%$ of osteoporotic women had waist hip ratio of $>.85$, while women with normal bone health had waist hip ratio $<.85$, which showed statistically significant correlation of high waist hip ratio with low bone mineral density.

Table 4 shows that $85.71 \%$ of the osteoporotic women were underweight (BMI < 18.5), while women with normal bone mineral density had a normal BMI. $48.03 \%$ of the osteopenic women had normal BMI, $10.78 \%$ were underweight, $35.29 \%$ were overweight and $5.88 \%$ were class I obese.

\begin{tabular}{|c|c|c|c|c|}
\hline BMI & $\begin{array}{l}\text { Normal } \\
(\mathrm{N}=4)\end{array}$ & $\begin{array}{c}\text { Osteopenia } \\
(N=102)\end{array}$ & $\begin{array}{l}\text { Osteoporosis } \\
\qquad(\mathrm{N}=14)\end{array}$ & $\begin{array}{l}\text { Total } \\
(120)\end{array}$ \\
\hline $\begin{array}{c}\text { Underweight }(<18.525 \\
\left.\mathrm{kg} / \mathrm{m}^{2}\right)\end{array}$ & 0 & $\begin{array}{c}11(10.78 \%) \\
(47.82 \%)\end{array}$ & $\begin{array}{c}12(85.71 \%) \\
(52.17 \%)\end{array}$ & $23(19.67 \%)$ \\
\hline $\begin{array}{c}\text { Normal }(18.5-22.925 \mathrm{~kg} \\
\left.\qquad / \mathrm{m}^{2}\right)\end{array}$ & $\begin{array}{l}4(100 \%) \\
(7.27 \%)\end{array}$ & $\begin{array}{c}49(48.03 \%) \\
(89.09 \%)\end{array}$ & $\begin{array}{c}2(14.28 \%) \\
(3.63 \%)\end{array}$ & $55(45.83 \%)$ \\
\hline $\begin{array}{c}\text { Overweight (23- } 24.925 \\
\left.\mathrm{~kg} / \mathrm{m}^{2}\right)\end{array}$ & 0 & $\begin{array}{c}36(35.29 \%) \\
(100 \%)\end{array}$ & 0 & $36(30 \%)$ \\
\hline $\begin{array}{l}\text { Class } 1 \text { obese }(>25 \mathrm{~kg} / \\
\left.\mathrm{m}^{2}\right)\end{array}$ & 0 & $6(5.88 \%)$ & 0 & $6(5 \%)$ \\
\hline \multicolumn{5}{|c|}{ Table 4. Correlation of BMI with BMD } \\
\hline $\begin{array}{l}\chi 2=49.975, \text { degree of } \\
49.975)=<0.05\end{array}$ & freedom = & $6, \chi 2 /$ degree & of freedom & $33, P(\chi 2>$ \\
\hline
\end{tabular}

\begin{tabular}{|c|c|c|c|}
\hline $\begin{array}{c}\text { Serum } \\
\text { Magnesium } \\
\text { Level }\end{array}$ & $\begin{array}{c}\text { Normal } \\
(N=4)\end{array}$ & $\begin{array}{c}\text { Osteopenia } \\
(N=102)\end{array}$ & Osteoporotic $(\mathrm{N}=14)$ \\
\hline$<1.7(\mathrm{~N}=1)$ & 0 & $\begin{array}{c}1(0.98 \%) \\
(100 \%)\end{array}$ & 0 \\
\hline $17-2.2(\mathrm{~N}=99)$ & $\begin{array}{c}4(100 \%) \\
(4.04 \%)\end{array}$ & $\begin{array}{c}87(85.29 \%) \\
(87.87 \%)\end{array}$ & $\begin{array}{c}8(57.14 \%) \\
(8.08 \%)\end{array}$ \\
\hline$>2.2(\mathrm{~N}=20)$ & 0 & $\begin{array}{c}14(13.72 \%) \\
(70 \%)\end{array}$ & $\begin{array}{c}6(42.85 \%) \\
(30 \%)\end{array}$ \\
\hline \multicolumn{4}{|c|}{ Table 5. Correlation of Serum Magnesium Level with BMD } \\
\hline $2=8.471$, degre & freedon & $P=0.07$ & \\
\hline
\end{tabular}

Table 5 shows that most of the women with normal bone mineral density (100\%), osteopenia (85.29\%) and osteoporosis (57.14\%) had normal serum magnesium level.

\section{DISCUSSION}

Osteoporosis is a public health problem worldwide and is a common disease in the older population, especially in postmenopausal women. In this study, prevalence of osteopenia (85 \%) and osteoporosis (11.67 \%) was very high, may be due to most women belonging to lower socioeconomic status with nutritional deficiency and lack of awareness. A number of studies have been conducted in countries of the Middle East; the prevalence of osteoporosis was estimated to be ranging from $13-31 \%$ in women. Several studies have shown that in addition to risk factors such as aging, lack of physical activity, smoking, premature menopause, family history, poor diet and low intake of calcium and vitamin $\mathrm{D}$, other factors like BMI and weight are also important risk assessment tools, which contribute to osteoporosis and osteoporotic fracture risk. ${ }^{4}$ Calcium and vitamin D has definite role in bone formation while other nutrient like magnesium might have some role in bone metabolism. $\mathrm{Mg}$ and $\mathrm{Ca}$ are closely related due to the presence of approximately 50 - $60 \%$ of total $\mathrm{Mg}$ in the bones along with calcium phosphate. $\mathrm{Mg}$ is an important ion due to its catalytic activity in the various metabolic process. So, evaluation of Mg might be helpful in bone homeostasis, especially in post-menopausal women with osteopenia and osteoporosis.

Some studies showed that BMD reduce with advancing age as shown in this study. ${ }^{7,8,9}$ In our study we found about $70 \%$ of osteoporotic women were over the age of 50 year. $83.33 \%$ of osteoporotic women belonged to the age group of more than 60 year, while small number of women who had normal BMD belonged to $<40$ year of age group. (P-value $<0.05$ ). With advancing age, bone resorption is faster than the new bone 
formation, calcium absorption decreased with age. $88.57 \%$ women with age group of 30 - 39 year are osteopenic. It may be due to high incidence of osteopenia in this area or due to lack of nutrition. None of the women were with normal BMD after 40 years of age. In females after menopause, prevalence of osteoporosis increases due to lack of oestrogen which increases osteoclastic activity and also decreases receptor of vitamin D in osteoblast which lead to osteoporosis. ${ }^{5}$ In these studies $100 \%$ women with normal BMD belonged to premenopausal age group, while $92.85 \%$ women with osteoporosis belonged to postmenopausal age group. Although $92.30 \%$ women of premenopausal age group were osteopenic, it may be due to high prevalence of osteopenia, while in postmenopausal women, $76.36 \%$ women were osteopenic and $23.63 \%$ women were osteoporotic. In this study, $85.71 \%$ osteoporotic women were underweight, while $100 \%$ women with normal BMI belonged to normal BMD. $89.09 \%$ women with normal BMI fell in osteopenic group (Pvalue $<0.05$ ), as prevalence of osteopenia was high in this study. In this study, low BMI correlated with low BMD, which was consistent with other study.7,10,9 In other ${ }^{11}$ they found no correlation with BMI with BMD. Another study showed that overweight men were associated with low BMD, 12 while other study reported that higher weight was associated with higher BMD. ${ }^{10,13}$ To reduce the risk of osteoporosis people were advised to maintain normal weight. Obesity is thought to be advantageous to maintain healthy bone but some studies showed that greater accumulation of body fat was associated with increased risk of low BMD, similar result was found in this study also. $78.57 \%$ osteoporotic women belonged to high risk group for waist hip ratio of 0.47 . Excessive body fat principally abdominal fat produces inflammatory cytokines which stimulate bone resorption and reduce bone strength. In osteoporotic and osteopenic group, we didn't find any correlation of BMD with decreased serum Mg level while other studies showed lower serum concentration of $\mathrm{Mg}$ in osteopenic and osteoporotic group. ${ }^{13}$ Another study of elderly Chinese women, Wang et al. observed a higher concentration of Mg in women with osteoporosis and osteopenia compared to normal women and inverse relation between serum Mg and serum Ca was observed. ${ }^{14}$

\section{CONCLUSIONS}

BMD has direct relationship with BMI and age. Maintenance of normal weight, exercise and lifestyle modification can prevent bone loss.

Data sharing statement provided by the authors is available with the full text of this article at jemds.com.

Financial or other competing interests: None.

Disclosure forms provided by the authors are available with the full text of this article at jemds.com.

\section{REFERENCES}

[1] Fritz MA, Speroff L. Clinical gynaecological endocrinology and infertility. $8^{\text {th }}$ edn. Lippincott Williams and Wilkins 2010.

[2] Unnanuntana A, Gladnick BP, Eve Donnelly E, et al. The assessment of fracture risk. J Bone Joint Surg Am 2010;92(3):743-53.

[3] Johnell 0, Kanis JA. An estimate of the worldwide prevalence and disability associated with osteoporotic fractures. Osteoporos Int 2006;17(12):1726-33.

[4] Qaradakhy TA, Mahmoud TA, Ahmed RA. Bone mineral density value among postmenopausal women and it's correlation with body mass index in Suleiman Governorate. IOSR Journal of Dental and Medical Science 2015;14(2):110-14.

[5] Castiglione S, Cazzaniga A, Albisetti W, et al. Magnesium and osteoporosis: current state of knowledge and future research directions. Nutrients 2013;5(8):3022-33.

[6] Bacopoulou F, Efthymiou V, Landis G, et al. Waist circumference, waist-to-hip ratio and waist-to-height ratio reference percentiles for abdominal obesity among Greek adolescents. BMC Pediatr 2015;15:50.

[7] Soltani A, Larijani B, Khashayar P, et al. The relationship between anthropometric parameters and bone mineral density in an Iranian referral population. Acta Med Iran 2014;52(7):505-10.

[8] Lu H, Fu X, Ma X, et al. Relationships of percent body fat and percent trunk fat with bone mineral density among Chinese, black and white subjects. Osteoporos Int 2011;22(12):3029-35.

[9] Montazerifar F, Karajibani M, Alamia S, et al. Age, weight and body mass index effect on bone mineral density in postmenopausal women health scope. 2014;3(2):e14075.

[10] Salamat MR, Salamat AH, Abedi I, et al. Relationship between weight, body mass index and bone mineral density in men referred for dual-energy x-ray absorptiometry scan in Isfahan, Iran. J Osteoporos 2013;2013:205963.

[11] Bansal S, Bansal A. Relation between obesity and osteoporosis in women. International Journal of Medical and Dental Sciences 2017;6(1).

[12] Fawzy T, Muttappallymyalil J, Sreedharan J, et al. Association between body mass index and bone mineral density in patients referred for dual-energy x-ray absorptiometry scan in Ajman, UAE. J Osteoporos 2011;2011:876309.

[13] Sharma R, Sharma P, Kumar P, et al. Role of magnesium in post-menopausal women with osteoporosis with osteopenia. Asian J Pharm Clin Res 2016;9(1):198-9.

[14] Wang S, Lin S, Zhou Y. Changes of total content of serum magnesium in elderly Chinese women with osteoporosis. Biol Trace Elem Res 2006;110(3)223-31 